2020, Vol: 21, pp. 139-152, DOI: 10.18038/estubtda. 829712

\title{
ADSORPTION BEHAVIOUR OF IONIC AND NON-IONIC SURFACTANTS ONTO TALC A NATURALLY HYDROPHOBIC MINERAL-A COMPARATIVE STUDY
}

\author{
Sedef DİKMEN ${ }^{1, *(i)}$, Bahri ERSOY ${ }^{2}$ (iD), Zafer DİKMEN ${ }^{1}$ \\ ${ }^{1}$ Department of Physics, Faculty of Science, Eskişehir Technical University, Eskişehir, Turkey \\ 2 Department of Mining Engineering, Faculty of Engineering, Afyon Kocatepe University, Afyonkarahisar, Turkey
}

\begin{abstract}
In present study, the adsorption behaviour of surfactants which are cationic (hexadecyltrimethylammonium bromide, HTAB), anionic (sodium dodecyl sulphate, SDS) and non-ionic (Triton X-100, TX-100) onto naturally hydrophobic talc were investigated. In this scope, a series of batch adsorption tests at natural $\mathrm{pH}$ were performed to determine adsorption isotherms and zeta potential (ZP) measurements of the ionic and non-ionic surfactants onto talc surfaces were measured using electrophoresis technique. To understand the mechanism of the adsorption process, the adsorption of ionic and non-ionic surfactants was studied as a function equilibrium concentration $(\mathrm{mol} / \mathrm{L})$. The amount of maximum adsorption of the surfactants onto talc are ordered as in the following: TX-100 $\left(9.0 \times 10^{-5} \mathrm{~mol} / \mathrm{m}^{2}\right) \sim \mathrm{HTAB}\left(8.5 \times 10^{-5} \mathrm{~mol} / \mathrm{m}^{2}\right)>\mathrm{SDS}\left(5.32 \times 10^{-5} \mathrm{~mol} / \mathrm{m}^{2}\right)$. Even though both the SDS and talc have negative surface charge, SDS can adsorb onto talc. Moreover, a good correlation was obtained between the adsorption isotherms and the zeta potential curves. Considering their adsorption isotherms, the ionic surfactants were showed different adsorption behavior concerning the non-ionic surfactant molecules. The adsorption isotherms of TX-100 and SDS increase rapidly in a narrow concentration range until the plateau region, while such a sharp increase does not appear for HTAB. The maximum adsorption amount of TX-100 and HTAB is greater than SDS. The results indicate that hydrophobic interaction and hydrogen bonding play a decisive role on the adsorption of non-ionic and anionic surfactants onto talc a naturally hydrophobic mineral, whereas electrostatic interaction becomes more important in the adsorption of cationic surfactant.
\end{abstract}

Keywords: Talc, Surfactant, Adsorption, FT-IR, Zeta Potential

\section{INTRODUCTION}

Talc is a clay mineral used in many different industries because of its unique physical and chemical properties [1]. It is a 2:1 phyllosilicate mineral containing sheets of magnesium octahedral (O) and silica tetrahedral $(\mathrm{T})$ is described as a hydrous magnesium silicate having the ideal chemical formula $\mathrm{Mg}_{3}\left(\mathrm{Si}_{2} \mathrm{O}_{5}\right)_{2}(\mathrm{OH})_{2}$. The theoretical chemical composition of $63.5 \mathrm{wt} . \%$ of $\mathrm{SiO}_{2}, 31.7$ wt.\% of $\mathrm{MgO}$, and 4.8 wt.\% of $\mathrm{H}_{2} \mathrm{O}$ [2]. Small amount of $\mathrm{Al}^{3+}$ can substitute for $\mathrm{Si}^{4+}$ ions in the silica tetrahedral sheet [3], and small to moderate amounts of $\mathrm{Al}^{3+}, \mathrm{Fe}^{2+}$ or $\mathrm{Fe}^{3+}$, can substitute for $\mathrm{Mg}$ in the octahedral sheet [4].

It is known that talc actually exhibits a heterogeneous structure. It has a naturally hydrophobic character (contact angle $\approx 80^{\circ}$ ), which is related to their sheet structure and especially to the basal plane areas containing silica tetrahedron bonds. The hydrophilic sites (edge or lateral surface), resulting from the breaking of the sheets during grinding, show the wetting behavior due to the occurrence of - $\mathrm{OH}$ groups (essentially silanol) and available for adsorbing hydrophilic (polar) molecules [5]. On the other hand, the hydrophobic sites (basal surface) consists of a tetrahedral siloxane surface with inert $-\mathrm{Si}-\mathrm{O}-\mathrm{Si}-$ links and are responsible for the adsorption of hydrophobic (nonpolar) molecules (Figure 1). The ratio between hydrophilic and hydrophobic sites, which reflects the contribution of substituting ions into the mineral crystal lattice, is of great importance in characterizing the adsorption properties of talc [6]. The presence of these nonpolar sites inside the talc particle shows hydrophobicity, which leads to the naturally floatable of talc. In addition, this hydrophobic behavior of talc affects the aggregation, dispersion and other wetting related processes of the mineral. Because of these characteristics, talc is

*Corresponding Author: sdikmen@eskisehir.edu.tr

Received: 30.10.2020 Published: 27.11.2020 
used in many industrial applications including paint, cosmetics, pharmaceuticals, pesticides, paper, food, plastics, ceramics and textiles, as known from the literature $[4,7,8]$.

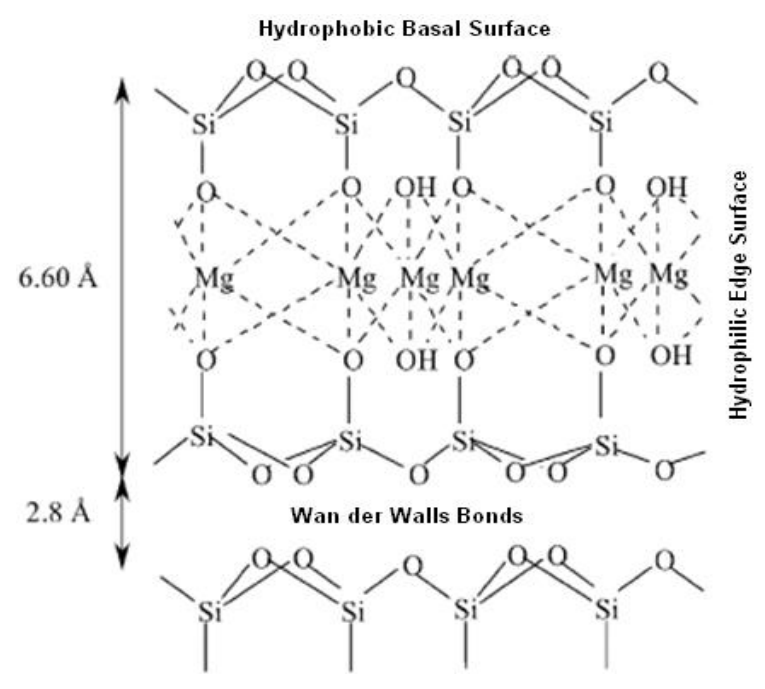

Figure 1. Schematic diagram of the crystal structure of talc

Surfactants are organic molecules that can form spherical structures called micelles in various solvents, consisting of a polar head group and a non-polar tail group. If they are dissolved in polar solvent like water, the head part is polar or ionic and shows hydrophilic character, while the chain part (linear or branched alkyl chain) is hydrophobic. Hence, a surfactant molecule has both a water soluble component and a water insoluble component [9]. When dissolved in a solvent at low concentration, can adsorb or locate at solid-liquid interfaces and therefore significantly change the physical properties of these interfaces. This adsorption behaviour can be attributed to the solvent structure and the chemical structure of surfactants combining both a polar and a non-polar group in a single molecule [10].

Depending upon the nature of the polar head group, surfactants can be classified into different classes. Among the different surfactant classes, cationic surfactants have positively charged head groups (e.g. trimethyl ammonium ion, $\left.-\mathrm{N}\left(\mathrm{CH}_{3}\right)_{3}{ }^{+}\right)^{-}$and are mainly involved in applications related to adsorption on surfaces. Surfaces are usually negatively charged (e.g. minerals, metal, plastics, fibers and cell membranes) so they can be modified when treated with cationic surfactants. For this reason, they are used as anti-corrosion and antistatic agents, flotation collectors, fabric softeners, conditioners and bactericides. Anionic surfactants are known as the products having one or more functional groups that ionise in water to produce negatively charged ions. They consist of negatively charged head group, like, sulphate $\left(-\mathrm{OSO}_{3}{ }^{-}\right)$sulfonates $\left(-\mathrm{SO}_{3}{ }^{-}\right)$and carboxylates $\left(-\mathrm{COO}^{-}\right)$groups used in soaps, detergents, personal care products and emulsifiers. Non-ionic contain groups that have a strong affinity for water due to strong dipole-dipole interactions resulting from hydrogen bonding, such as ethoxylates $\left[-\left(\mathrm{OCH}_{2}\right.\right.$ $\left.\mathrm{CH}_{2}\right) \mathrm{mOH}$. An advantage over ionic is that the length of both hydrophilic and hydrophobic groups can be varied to achieve maximum efficiency in utilization [9-10]. Due to the characteristic properties of surfactants, that are used in a wide variety of industrial processes and household, such as cleaning, food, agrochemicals, metallurgy, pharmaceuticals, paints, paper coatings, printing inks, ceramics, mining and others.

It is well known in the literature that clays such as kaolinite, bentonite, sepiolite etc. are not only applied as crude clays for the remediation of contaminated waters but also very often as organo-clays in which the cations are exchanged with organic ones to modify the surface of clays. Cationic surfactants are typically used to modify hydrophilic mineral surfaces e.g. of clay and some natural zeolites which are 
known as surfactant-modified clay (SMC) or surfactant modified-zeolite (SMZ) [12-14]. Wang et al. (2004) [15] showed that soil modified with HTAB is most effective in removing the aromatic-type organic contaminants. Some authors have reported that soils and waters polluted by hydrophobic organic compounds have encouraged research into the use of anionic and non-ionic surfactants as potential agents for the enhanced solubilization and removal of contaminants from soils and sediments [16, 17]. Numerous studies of clay or soil minerals have been carried out, some of which constitute adsorption of TX-100, SDS and ODTMA onto different clay minerals [18], adsorption isotherms of TX-100, TX-305 and TX-405 on four different solids, adsorption of one cationic (HDTMA) and three anionic (DOWFAX-8390), STEOL-CS330 and Aerosol-OT) surfactants onto different sorbents (alumina, zeolite, and Canadian River Alluvium) [19], and adsorption of three different types of surfactants onto the soil [20].

Although there have been systematic studies on the effect of surfactant properties on adsorption for some clay and soil minerals, there is no study on the talc/surfactant system in the literature.

This study aimed to provide background information. In this scope, a series of adsorption studies were carried out on talc with three surfactants with different chemical structures by correlating the adsorption isotherms and zeta potential curves. Furthermore, characterization studies were performed on the natural talc and surfactants /talc system. Thermal and spectroscopic methods were carried out such as infrared spectroscopy (FT-IR), thermogravimetric analysis (TGA).

\section{MATERIALS AND METHODS}

\subsection{Materials}

Commercial ground talc $(<40 \mu \mathrm{m})$ sample was used in this study provided by Hasbay Mining Co. (Turkey). The chemical composition of talc used was determined by X-ray fluorescence (Bruker, S8 Tiger WDXRF and the result is given in Table 1.

X-ray diffraction (XRD) analysis (Bruker D8 Advance Diffractometer) of talc without further treatment revealed the presence of various impurities and its purity is $\sim 80 \mathrm{wt} \%$ talc. The XRD data indicated that the sample used is the major component of the talc with characteristic features at $d=9.36 \AA\left(2 \theta=9.44^{\circ}\right)$, $\mathrm{d}=4.67 \AA\left(2 \theta=18.95^{\circ}\right), \mathrm{d}=4.58 \AA\left(2 \theta=19.34^{\circ}\right), \mathrm{d}=3.55 \AA\left(2 \theta=25.01^{\circ}\right)$ and $\mathrm{d}=3.11 \AA\left(2 \theta=28.60^{\circ}\right)$ (Figure 2).

The specific surface area of talc sample was measured as $8.14 \mathrm{~m}^{2} / \mathrm{g}$ by the BET method (Quantachrome Instruments, Nova 2200).

Cationic surfactant, hexadecyltrimethylammonium bromide (HTAB) from Fluka Chem. Co. (99\% purity), an anionic surfactant, sodium dodecyl sulphate (SDS) from Merck Chem. Co. (99\% purity) and a non-ionic surfactant, 4-(1, 1, 3, 3-tetramethylbuthyl) phenyl-polyethylene glycol (Triton X-100) from Sigma-Aldrich Chem. Co. (99\% purity) were used in the adsorption tests.

Table 1. Chemical composition of talc.

\begin{tabular}{llllllll}
\hline Elements & $\mathrm{SiO}_{2}$ & $\mathrm{MgO}$ & $\mathrm{Al}_{2} \mathrm{O}_{3}$ & $\mathrm{Fe}_{2} \mathrm{O}_{3}$ & $\mathrm{CaO}$ & Others & LOI \\
\hline Weight (\%) & 44.35 & 27.08 & 3.29 & 6.10 & 6.18 & 1.06 & 11.94 \\
\hline
\end{tabular}

LOI: Loss on Ignition 


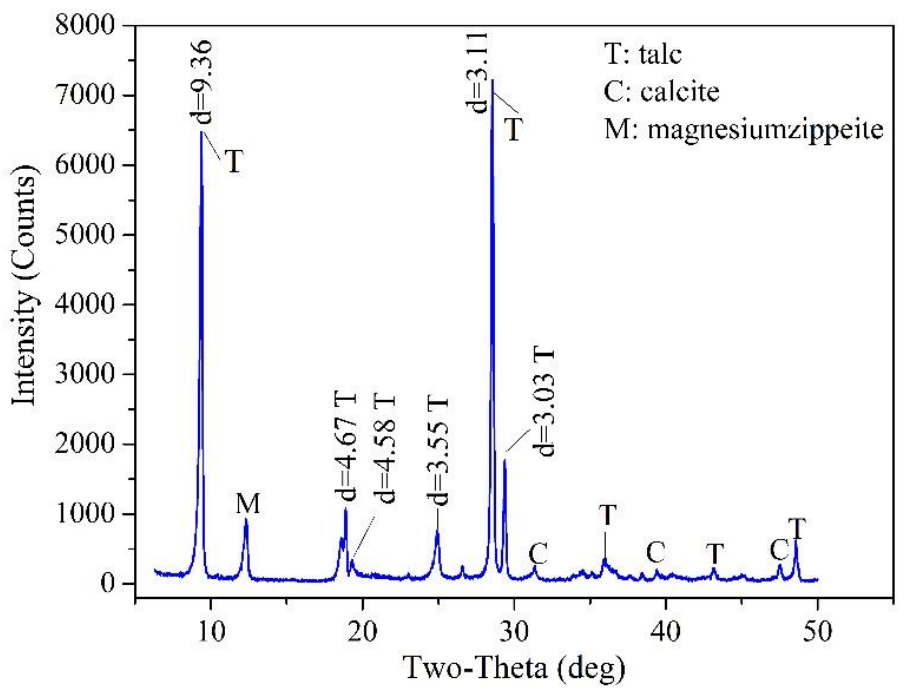

Figure 2. XRD pattern of talc used in experimental studies

Table 2. Some properties of selected surfactants in this study

\begin{tabular}{lll}
\hline Compound & Molecular formula & $\begin{array}{l}\text { Molecular weight } \\
(\mathbf{g} / \mathbf{m o l})\end{array}$ \\
\hline $\mathrm{HTAB}$ & $\mathrm{C}_{16} \mathrm{H}_{33}\left(\mathrm{CH}_{3}\right)_{3} \mathrm{NBr}$ & 364.46 \\
\hline $\mathrm{SDS}$ & $\mathrm{CH}_{3}\left(\mathrm{CH}_{2}\right)_{11} \mathrm{OSO}_{3} \mathrm{Na}$ & 288.38 \\
\hline $\mathrm{TX}-100$ & $\left(\mathrm{C}_{8} \mathrm{H}_{17}\right) \mathrm{C}_{6} \mathrm{H}_{4}\left(\mathrm{OCH}_{2} \mathrm{CH}_{2}\right)_{n} \mathrm{OH}, \mathrm{n} \sim 10$ & 624.00 \\
\hline
\end{tabular}

\subsection{Methods}

Adsorption isotherms of surfactants by talc were obtained using the batch equilibrium technique. A solid/solution ratio of $2 \%$ wt. was used to the study adsorption of HTAB, SDS and TX-100. A series of surfactant aqueous solutions at concentrations ranging from $1 \times 10^{-3}$ to $3 \times 10^{-2} \mathrm{M}$ was used for adsorption experiments. The suspensions were shaken in a thermostatted shaker (at $25^{\circ} \mathrm{C} \pm 1$ ) for $2 \mathrm{~h}$ to reach equilibrium. Then, they were centrifuged at $3500 \mathrm{rpm}$ for $15 \mathrm{~min}$ to obtain a clear supernatant solution. Aliquots were taken from the supernatant solutions and analyzed by UV-spectrophotometer (HachLange, DR5000) using Hach-Lange special test kits for each surfactant. For HTAB analysis, UV test kits LCK331 (concentration range 0.2-2 mg/ /) and LCK335 (concentration range 0.2-20 mg/L) were used. SDS analysis was performed with LCK332 (0.2-2 mg/L) and LCK330 (0.2-20 mg/L) UV test kits. Finally, LCK333 UV test kits were used for TX-100 analysis. The adsorption capacity was calculated by the formula given elsewhere as follows:

$$
Q=\frac{\left(\mathrm{C}_{\mathrm{i}}-\mathrm{C}_{\mathrm{e}}\right)}{\mathrm{Sxmx} 1000} V
$$

where $C_{\mathrm{i}}$ and $C_{\mathrm{e}}$ represents the initial and final solution concentrations in mol/L, respectively.

$m$ is the weight of solid (g),.$V$ is the solution volume $(\mathrm{L}), \mathrm{S}$ is the specific surface area of talc and $Q$ is the adsorption capacity $\left(\mathrm{mol} / \mathrm{m}^{2}\right)$. 
The zeta potential measurements were carried out with a Malvern ZS90 Zetasizer using He-Ne red laser beam $(\lambda: 633 \mathrm{~nm})$ through M3-PALS (Mixed Mode Measurement Phase Analysis Light Scattering) technique. This instrument measures the zeta potential of the particle according to the electrophoresis method. After the adsorption process, solid-liquid separation was made by centrifugation. A $0.75 \mathrm{ml}$ sample was taken from the aliquot using a syringe and placed in the cell of the zeta meter. Then, a very small amount of talc particles was taken from the bottom of the centrifuge tube and added to the zeta cell. After the cell was shaken well, it was placed in the instrument. The average of ten measurements was taken to represent the measured potential. The applied voltage during the measurements generally varied in the range of $50-100 \mathrm{~V}$.

FT-IR spectra for talc and surfactant adsorbed talc were obtained on a Bruker IFS-66 series Fourier transform infrared spectrometer to confirm the surfactant adsorption. FTIR spectra were recorded, in the range of 400-4000 cm $\mathrm{cm}^{-1}$ at a resolution of $4 \mathrm{~cm}^{-1}$ with $\mathrm{KBr}$ pellets technique. Previous analysis, $100 \mathrm{mg}$ $\mathrm{KBr}$ powder and $1 \mathrm{mg}$ powder talc were mixed in an agate bowl, and pressed using a hydraulic press to obtain disc shaped pellet samples.

Thermogravimetric analysis (TGA) of the talc and surfactant adsorbed talc samples were carried out by a Setaram Setsys 1750 instrument. The samples were heated in an $\mathrm{Al}_{2} \mathrm{O}_{3}$ crucible in the temperature range $30-400{ }^{\circ} \mathrm{C}$ with a heating rate of $10{ }^{\circ} \mathrm{C} \mathrm{min}{ }^{-1}$. Approximately $30 \mathrm{mg}$ of sample was used in each run.

\section{RESULTS AND DISCUSSION}

\subsection{Adsorption Isotherms and Zeta Potential Curves}

The adsorption isotherms of HTAB, SDS and TX-100 onto talc are shown in Figure 3, and the zeta potential curves of talc as a function of the equilibrium concentration of these surfactants are shown in Figure 4. Both figures are used to explain the mechanism of surfactant adsorption on talc. Although the mechanisms that enable the adsorption of all three surfactants on talc are the same, the effectiveness of these mechanisms are different due to the nature of surfactants, and the amount of adsorption varies at the same equilibrium concentration. The adsorption isotherms typically exhibit three regions in Figure 3. It was suggested that in region I the HTAB monomers are electrostatically adsorbed to the surface, with head groups in contact with the surface. Hydrocarbon tail groups may interact with any hydrophobic regions of the surface. Here, the most significant two mechanisms responsible for cationic surfactant adsorption on talc surface are ion exchange and hydrophobic interaction. Ion exchange is a stoichiometric chemical reaction between two phases with electrical neutrality of each phase being maintained throughout the exchange process and the method can simply be considered as specific occurrence of adsorption. On the other hand, hydrocarbon chains in solution can associate with each other in such a way that contact between the solution and the hydrophobic regions is minimized. This is known as hydrophobic interaction in the bulk the solution and controlled by van der Waals interactions.

It was suggested that in region I the HTAB monomers are electrostatically adsorbed to the surface, with head groups in contact with the surface. In this region, both adsorption mechanisms, ion exchange and hydrophobic interactions, are effective. However, region I is controlled by the ion-exchange mechanism only and this is inferred from ZP curve. In the region where HTAB adsorption increased, ZP values increased slightly from $-26 \mathrm{mV}$ to $-15 \mathrm{mV}$. In region II, the HTAB is governed by hydrophobic interactions between the surfactant chains. Finally, in region III, the surface morphology is assumed a fully formed bilayer. Further increases in the solution surfactant concentration do not lead to any further increases in the surface excess [21]. 
When the HTAB isotherm in Figure 3 is examined, from the point where the ion exchange capacity ends on the curve, HTAB cation with positively charged polar group adsorbs to the surface of talc with a negative surface charge through electrostatic interaction, increasing the adsorption capacity slightly. Meanwhile, with the increase in concentration, the amount of adsorption between the hydrocarbon chains of HTAB molecules simultaneously with the electrostatic interaction increases with the effect of van der Waals attraction forces and a value of $4.78 \times 10^{-6} \mathrm{~mol} / \mathrm{m}^{2}$ is reached at $2.37 \times 10^{-7} \mathrm{M}$ equilibrium concentration $\left(\mathrm{C}_{\mathrm{e}}\right)$. It should be emphasized here that the $2.37 \times 10^{-7} \mathrm{M}\left(\mathrm{C}_{\mathrm{e}}\right)$ value, which represents the beginning of region II, is also the last concentration value where the $\mathrm{ZP}$ curve in Figure 4 remains constant, and after this value, the bilayer or hemimicelle starts to form. After the equilibrium concentration of $2.37 \times 10^{-7} \mathrm{M}\left(\mathrm{C}_{\mathrm{e}}\right)$, the hydrophobic (chain-chain) interaction mechanism becomes even more effective by increasing the HTAB concentration even more. The adsorption amount of HTAB increases with the formation of hemimicelle and $2.82 \times 10^{-5} \mathrm{~mol} / \mathrm{m}^{2}$ at $8.23 \times 10^{-4} \mathrm{M}\left(\mathrm{C}_{\mathrm{e}}\right)$ and reaches its maximum adsorption capacity with a value of $6.31 \times 10^{-3} \mathrm{M}\left(\mathrm{C}_{\mathrm{e}}\right)$ with $8.5 \times 10^{-5} \mathrm{~mol} / \mathrm{m}^{2}$.

Non-ionic surfactant (TX-100) are physically adsorbed rather than electrostatically or chemisorbed. However, it differs from other surfactants in that; quite small change in concentration of the adsorbent can have a large effect on the adsorption. This is due to adsorbate-adsorbate and adsorbate-solvent interactions which cause surfactant aggregation in bulk solution and which lead to change in orientation and packing of surfactant at the surface [22].

The SDS isotherm exhibit three regions with distinctly different slopes. The first region (I), which is characterized by the molecular interaction, e.g. complexation or hydrogen bonding on the talc surface, extends up to approximately $4 \times 10^{-4} \mathrm{M}\left(\mathrm{C}_{\mathrm{e}}\right)$ SDS concentration. The first region I is characterized by the complexation of anionic surfactant with $\mathrm{Mg}^{2+}$ ions at the octahedral sheet or hydrogen bonding between the oxygen groups of anionic head groups of surfactant in the second region. The third region II indicates both the beginning of plateau region. The results obtained by Özdemir et al. (2007) [23] support this. Figure 4 also show that talc has negative ZP values with SDS and TX-100 surfactants at all concentrations. The talc in the presence of HTAB up to $1 \times 10^{-4} \mathrm{M}$ concentrations has negative $\mathrm{ZP}$ values. Above $1 \times 10^{-4} \mathrm{M}$ concentration, the $\mathrm{ZP}$ becomes positive, indicating that talc surfaces are completely covered by positive ions. As expected, as the concentration of anionic surfactant increases, the ZP of talc become more negative. The results also reveal that non-ionic surfactants cause the talc to have a slightly less negative ZP. The decrease in ZP becomes more pronounced with the increase in surfactant concentration. However, changes in the ZP magnitude with TX-100 is less than those of HTAB and SDS. Kaya \& Yükselen (2005) [24] who found that the anionic additives produced more negative ZP made similar observations. Non-ionic additives produced a more negative potential depending on ion and clay type compared to cationic additives. 


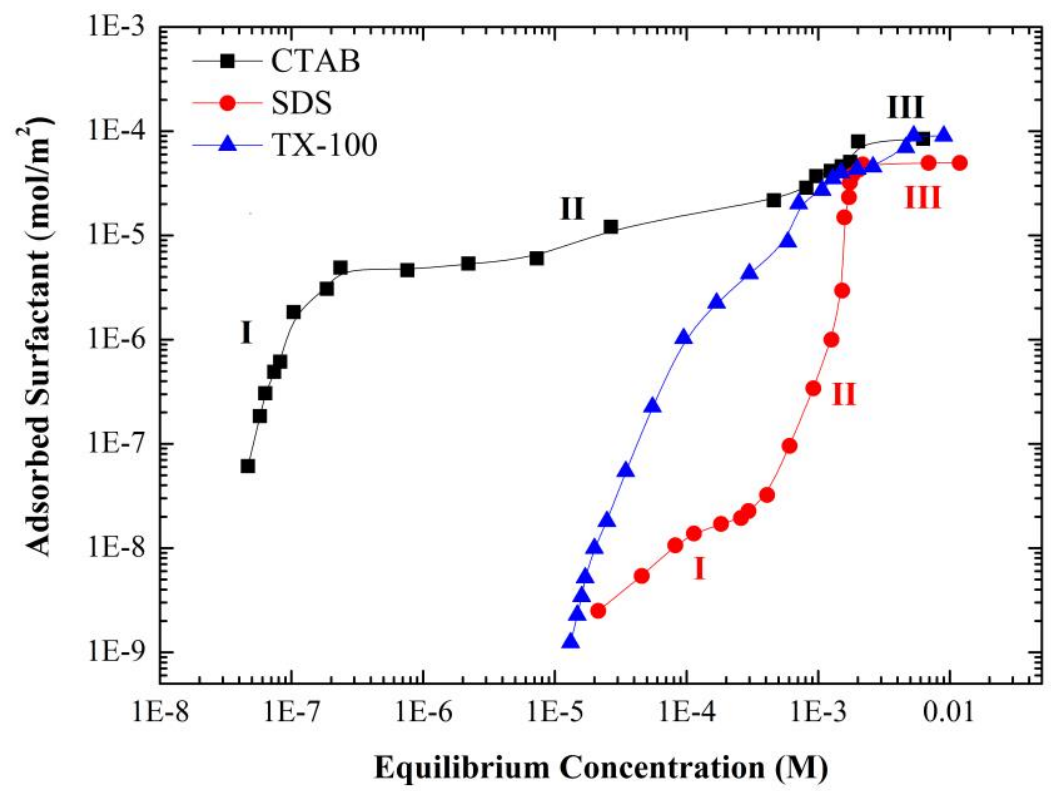

Figure 3. Adsorption isotherms of HTAB, SDS and TX-100 on talc (T: $\left.24 \pm 1^{\circ} \mathrm{C}, \mathrm{pH}: 7.8-9.7\right)$

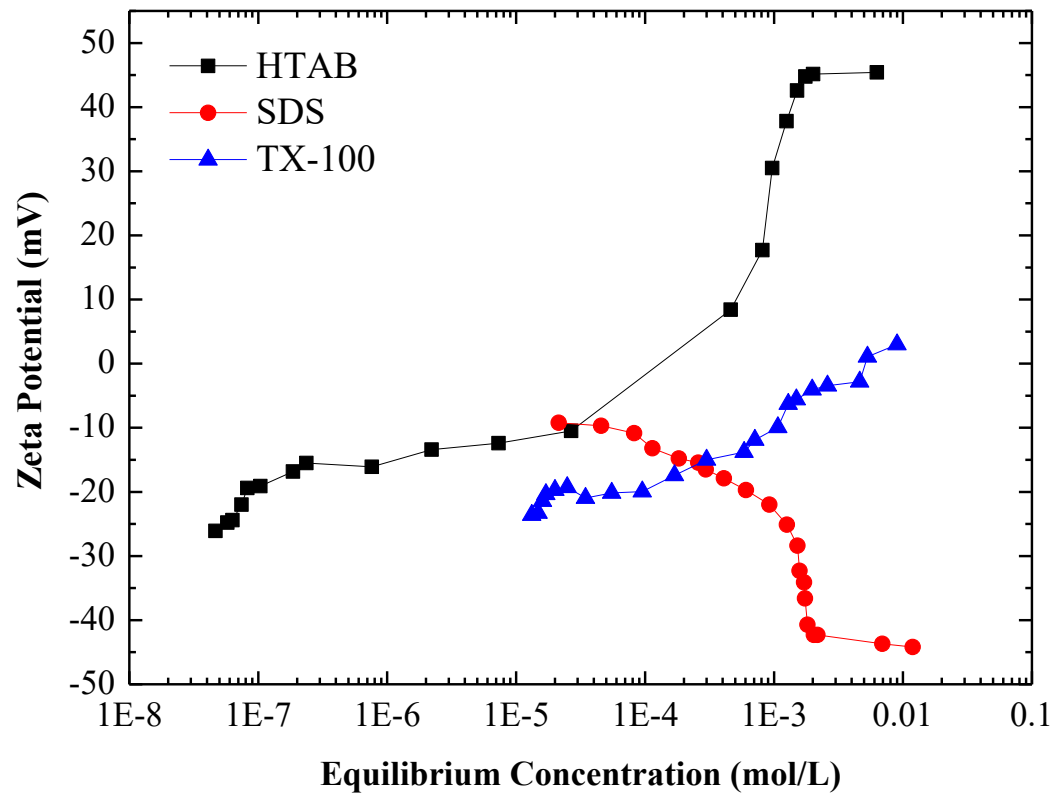

Figure 4. Zeta Potential of talc versus equilibrium concentration $\left(\mathrm{C}_{\mathrm{e}}\right)$ in the presence of surfactant $\left(\mathrm{T}: 24 \pm 1^{\circ} \mathrm{C}\right.$, $\mathrm{pH}:$ 7.8-9.7)

\subsection{Thermal Analysis}

Thermogravimetric (TGA) analysis assign the weight gain or loss of a material (e.g., minerals, glasses, ceramics, polymers) due to gas absorption or release as a function of temperature. Results of TG curves presented in Figures 5 (a) and (b), characterized the thermal behaviour of natural and surfactant/talc samples, respectively. The first region of weight loss, between 50 and $100^{\circ} \mathrm{C}$, was the result of the 
elimination of water physically adsorbed in the natural talc. In the temperature range from 500 to $700^{\circ} \mathrm{C}$, the weight loss was fast and corresponds to magnesite thermal decomposition, as well as to the dehydroxylation of the brucite sheet localized in the interlayer space of the talc. In the third region of weight loss, between 700 and $800^{\circ} \mathrm{C}$, a high weight loss rate could be observed due to calcite thermal decomposition and to talc dehydroxylation, since the structural water of 2:1 layer started to be eliminated at this temperature [25]. Since talc is almost thermally stable at $200-400^{\circ} \mathrm{C}$, the weight loss observed in talc/surfactant thermograms at this temperature range should be attributed to the decomposition of surfactant molecules (Figure 5-b). It can take place in a step, oxidation of organic hydrogen and formation of water and charcoal [26].

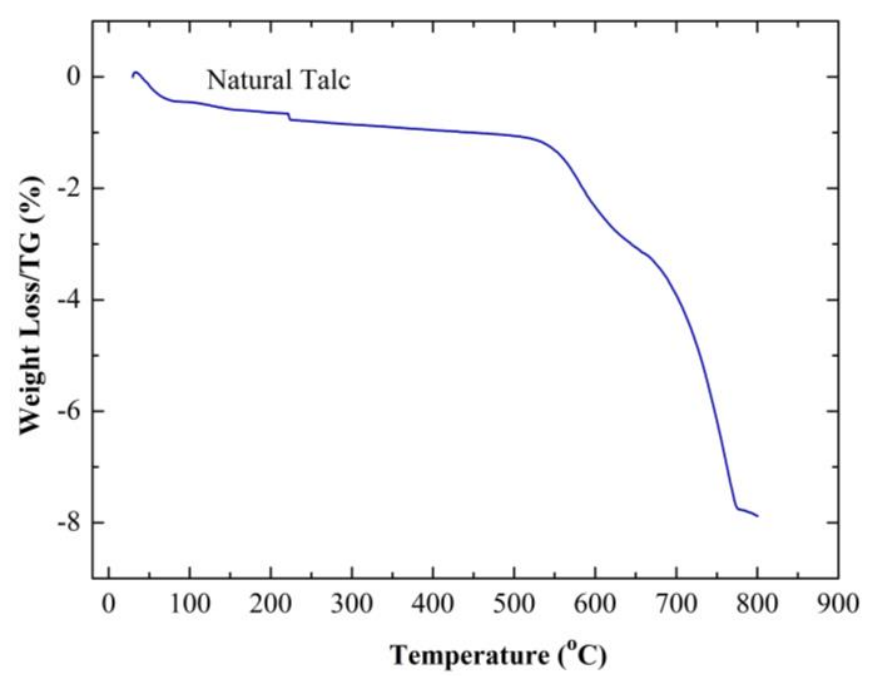

(a)

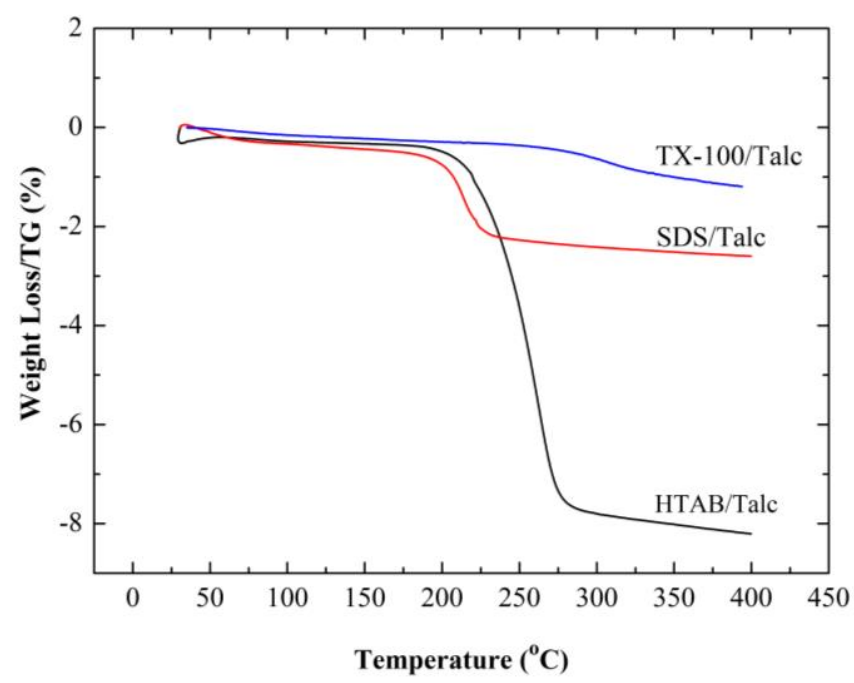

(b)

Figure 5. Thermogravimetric (TG) analysis of (a) raw talc in the range of $25-800{ }^{\circ} \mathrm{C}$ and (b) surfactant adsorbed talc (HTAB, SDS and TX-100) in the range of $25-400^{\circ} \mathrm{C}$ (The initial concentration for each surfactant is $5.5 \times 10^{-3} \mathrm{M}$.)

The amount water in $\mathrm{HTAB} / \mathrm{Talc}$ system decreases in relation to the natural talc as indicated by TG results, because the replacement of exchangeable cations by the cationic surfactant increases the hydrophobic character of the surface [27]. 
TG curves corresponding to the SDS-talc system indicate the low presence of the surfactant in agreement to the lower adsorbed amount of SDS than HTAB. It is estimated a little change in the temperature of water loss concerning the natural clay minerals, this could be due to the replacement of some of the water molecules by organic molecules [26].

Loss of TX-100 adsorbed by talc take place in a step between 300 and $400^{\circ} \mathrm{Cpossibly} \mathrm{due} \mathrm{to} \mathrm{the} \mathrm{presence}$ of surfactant adsorbed on the surface and in the interlayer space of this material or to decomposition of different units of TX-100 adsorbed in the interlayer space of talc [27].

\subsection{FT-IR Study}

Infrared spectroscopy uses successfully in the characterization of inorganic compounds as well as organic compounds. Table 3 includes the wavenumbers $\left(\mathrm{cm}^{-1}\right)$ of characteristic absorption bands in the spectra of HTAB, SDS and TX-100, and for the HTAB/talc, SDS/talc and TX-100/talc, as well as their assignment to functional groups, their vibrational. Figure 6 indicates the FTIR spectra of the natural talc; HTAB, SDS and TX-100; natural and treated with the different HTAB, SDS and TX-100.

The adsorption bands observed at $3677 \mathrm{~cm}^{-1}$ and $1422 \mathrm{~cm}^{-1}$ correspond to the fundamental hydroxyl group stretching vibrations (brucite layer) of talc arising from $v \mathrm{Mg}_{3} \mathrm{O}-\mathrm{H}$. Existence of this peaks stated can indicate the occurrence of iron in the crystal structure of talc. The observed strong band at around $1020 \mathrm{~cm}^{-1}$ is assigned to the out-of-plane symmetric stretching of $v_{3} \mathrm{Si}-\mathrm{O}-\mathrm{Si}$ groups of talc. The sharp absorption at $669 \mathrm{~cm}^{-1}$ is due to the stretching vibration of $\mathrm{Si}-\mathrm{O}-\mathrm{Mg}$ in talc structure [1, 26-29].

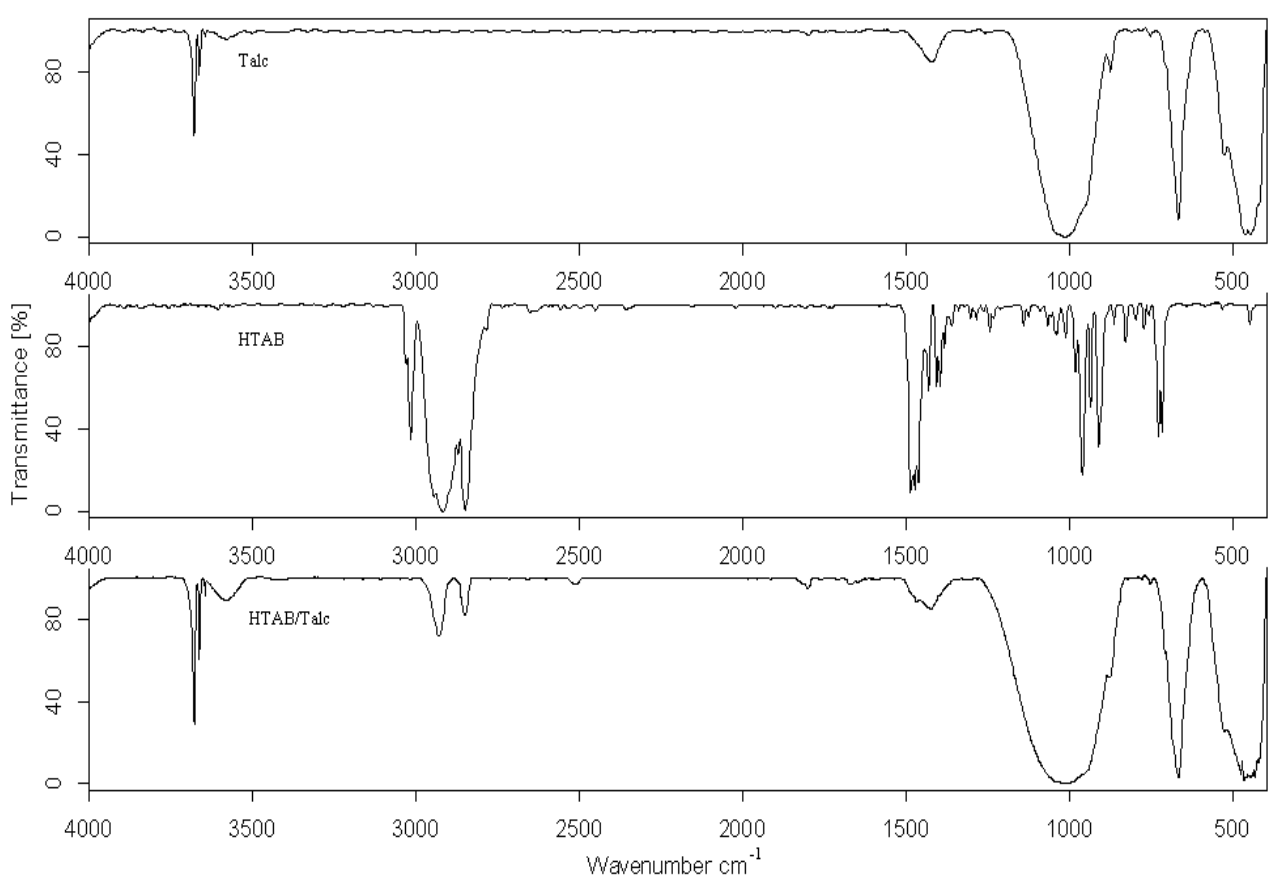

(a) 
Dikmen et al. / Eskişehir Technical Univ. J. of Sci. and Tech. A-Appl. Sci. and Eng. Vol. 21-2020

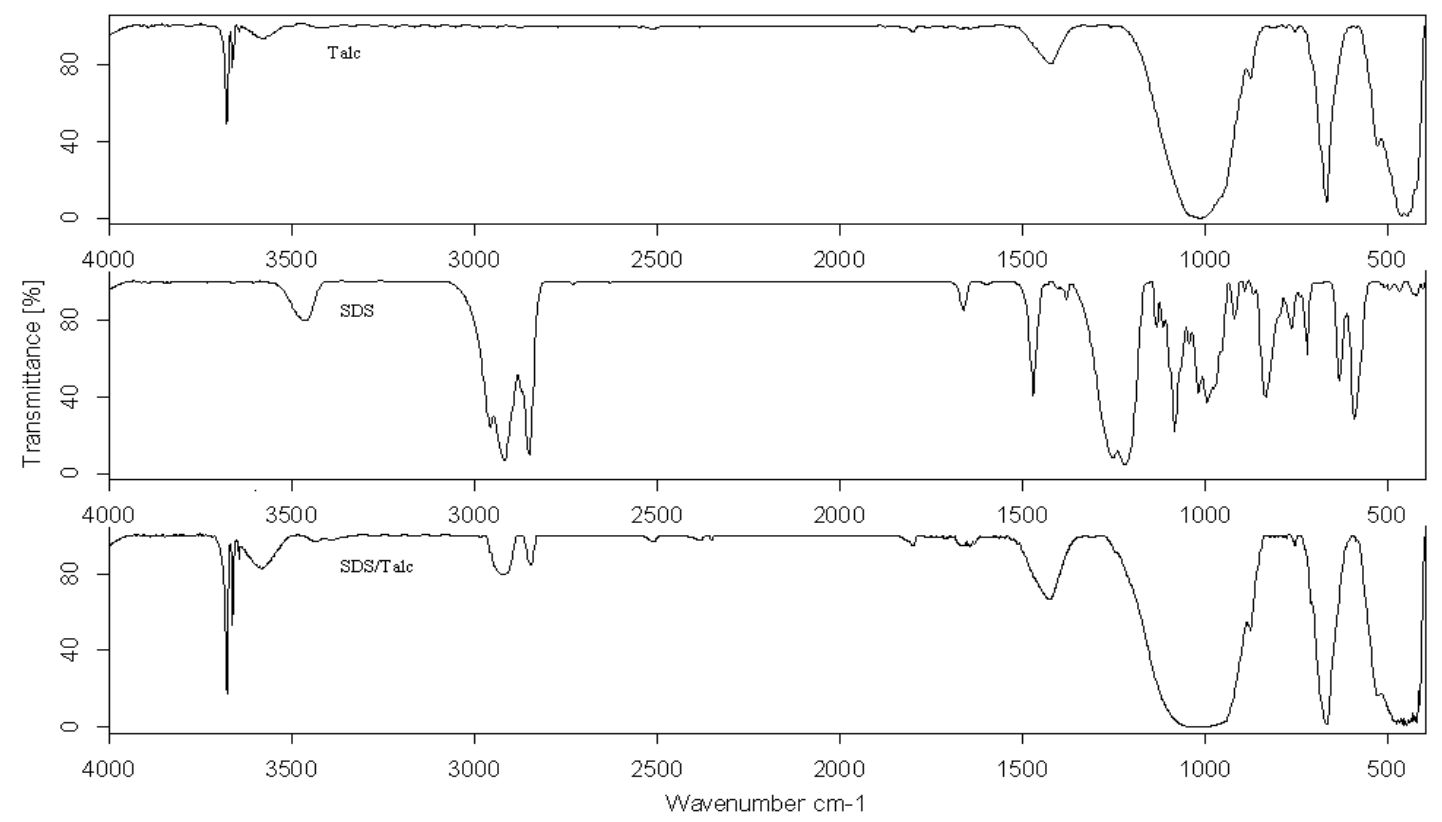

(b)

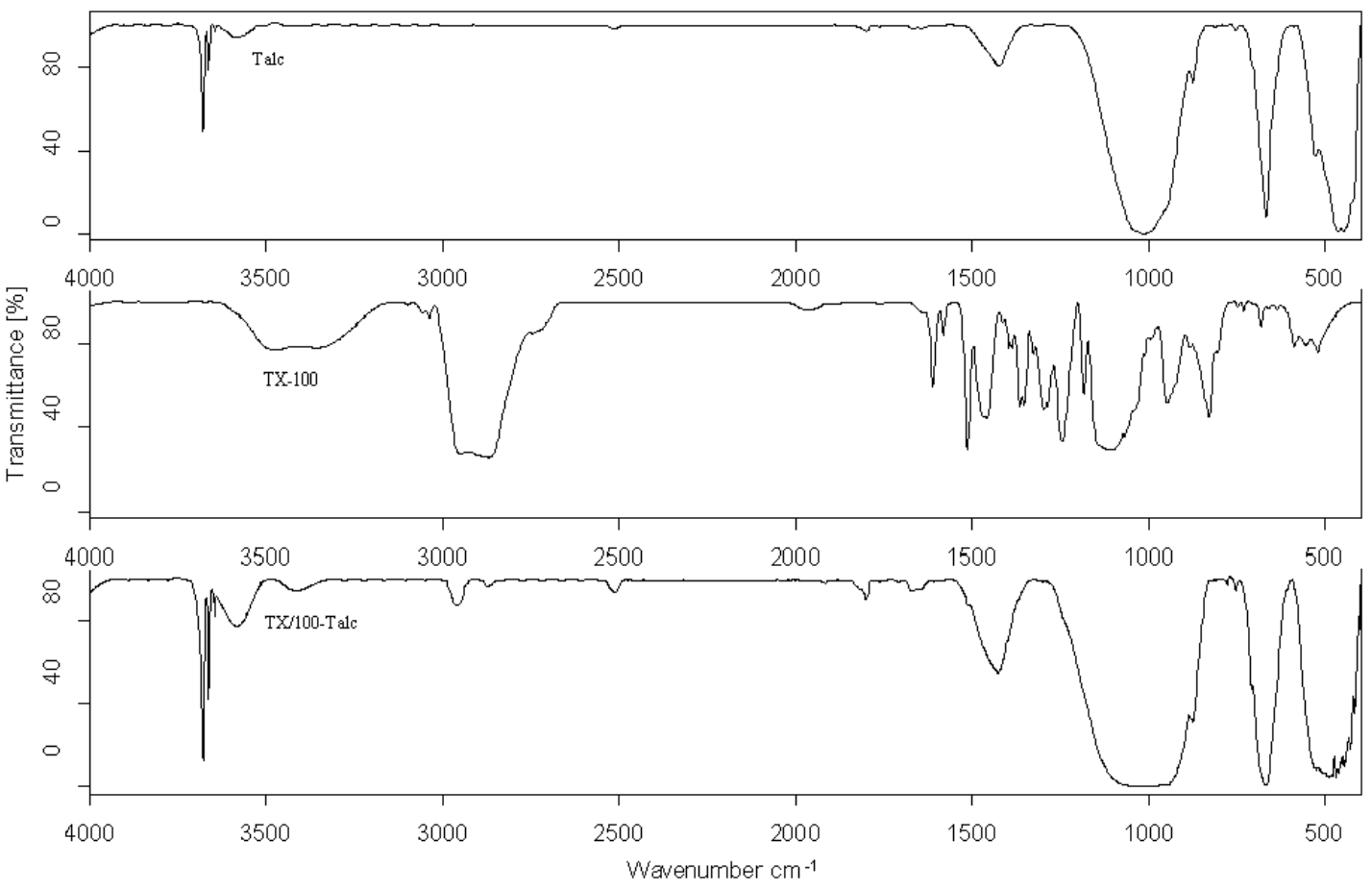

(c)

Figure 6. FT-IR spectra in the $400-4000 \mathrm{~cm}^{-1}$ region of (a) talc, HTAB adsorbed talc (b) talc, SDS and SDS adsorbed talc (c) talc, TX-100 and TX-100 adsorbed talc. (The initial concentration for each surfactant is $5.5 \times 10^{-3} \mathrm{M}$ ) 
Table 3. Wavenumbers $\left(\mathrm{cm}^{-1}\right)$ absorption bands of the FT-IR spectra for the natural talc, surfactants and surfactant/talc samples

\begin{tabular}{|c|c|c|c|c|c|c|c|}
\hline Sample & VOH & VоH $\mathbf{H}_{2} \mathrm{O}$ & $\delta \mathrm{OH}_{\mathbf{2}} \mathbf{O}$ & $\begin{array}{c}\text { asymmetric } v \text { - } \\
\text { CH }\end{array}$ & $\begin{array}{c}\text { symmetric } \\
\text { V-CH }\end{array}$ & $\delta$ - & $v$ co \\
\hline Natural Talc & 3677 & 3579 & 1642 & - & - & - & - \\
\hline НTAB & - & - & - & 2917 & 2849 & 1473 & - \\
\hline HTAB/Talc & 3677 & 3581 & 1635 & 2920 & 2850 & 1425 & - \\
\hline SDS & - & - & - & 2956, 2918 & 2850 & 1469 & - \\
\hline SDS/Talc & - & - & - & 2958,2921 & 2852 & 1421 & - \\
\hline TX-100 & - & 3472 & 1610 & 2950 & 2870 & 1457 & 1350 \\
\hline TX-100/Talc & 3677,3643 & 3415 & 1670 & - & 2872 & 1425 & - \\
\hline
\end{tabular}

The FT-IR spectra of the surfactant-talc show presence of absorption bands corresponding to adsorbed surfactant. Corresponding to the adsorbed water molecules show that not all the water was replaced by surfactant molecules. However, changes in wavenumbers of these bands are observed and they could show partial displacement of water by adsorbed surfactant.

The FT-IR spectra of the HTAB/Talc present modification in the $\mathrm{C}-\mathrm{H}$ stretching (at 2920 and 2850 $\mathrm{cm}^{-1}$ ) bending (at $1425 \mathrm{~cm}^{-1}$ ) of adsorbed HTAB compared to the pure HTAB. The results obtained are in accordance with the literature [26].

In the spectra of TX-100/talc, a displacement of the absorption band corresponding to the $-\mathrm{OH}$ bending vibration of adsorbed water is observed especially in the TX-100/talc. These observed bands corresponding to the $\mathrm{CO}$ bending vibrations $\left(1425 \mathrm{~cm}^{-1}\right)$ of the surfactant towards higher wavenumbers could indicate a possible ion-dipole interaction between the surfactant and adsorbent through the $-\mathrm{OH}$ group of TX-100 and water coordinated to the exchangeable cations of clay minerals [26]. The change in the absorption bands corresponding to $\mathrm{CH}_{2}$ stretching and bending modes of hydrocarbon chain groups of TX-100 (at $2870 \mathrm{~cm}^{-1}$ ) is also seen towards higher wavenumbers (Table 3). This displacement can be related to a reorganization of the organic compound molecules when an interaction with the talc is established [26].

\section{CONCLUSIONS}

- The amount of maximum adsorption of the surfactants onto talc are ordered as in the following: TX-100 $\left(9.0 \times 10^{-5} \mathrm{~mol} / \mathrm{m}^{2}\right) \sim \mathrm{HTAB}\left(8.5 \times 10^{-5} \mathrm{~mol} / \mathrm{m}^{2}\right)>\mathrm{SDS}\left(5.32 \times 10^{-5} \mathrm{~mol} / \mathrm{m}^{2}\right)$. The maximum adsorption amount of TX-100 and HTAB is greater than SDS. Even though both the SDS and talc have negative surface charge, SDS can adsorb onto talc. Moreover, a good correlation was seen between the adsorption isotherms and the zeta potential curves. The adsorption isotherms of TX100 and SDS increase rapidly in a narrow concentration range until the plateau region, while such a sharp increase does not appear for HTAB. The results show that hydrophobic interaction and hydrogen bonding play a decisive role in the adsorption of TX-100 and SDS onto talc a naturally hydrophobic mineral, whereas electrostatic interaction becomes more significant in the adsorption of HTAB. It can be stated that the presence of HTAB significantly decreases (makes more positive) the $\mathrm{ZP}$ of talc at a natural $\mathrm{pH}(\mathrm{pH} \sim 7.8-9.7)$. The presence of the SDS makes the $\mathrm{ZP}$ of the talc more negative in comparison with the TX-100.

- Considering the TGA analysis, the results showed an increase in stabilization of the cationic (HTAB) surfactant absorbed by talc compared to the anionic (SDS) and non-ionic (TX-100) surfactant type.

- The FT-IR spectra of the surfactant-talc show presence of absorption bands corresponding to adsorbed surfactant. The FT-IR spectra of the HTAB/talc present modification in the $\mathrm{C}-\mathrm{H}$ 
stretching (at 2920 and $2850 \mathrm{~cm}^{-1}$ ) bending (at $1425 \mathrm{~cm}^{-1}$ ) of adsorbed HTAB compared to the pure HTAB. In the FT-IR spectra of TX-100/talc, a displacement of the absorption band corresponding to the $-\mathrm{OH}$ bending vibration of adsorbed water is observed especially in the TX$100 /$ talc. The change in the absorption bands corresponding to $\mathrm{CH}_{2}$ stretching and bending modes of hydrocarbon chain groups of TX-100 (at $\left.2870 \mathrm{~cm}^{-1}\right)$ is also seen towards higher wavenumbers.

\section{ACKNOWLEDGEMENTS}

The authors would like to thank Tülay Tıraş (Eskişehir Technical University, Physics DepartmentSpectroscopy Laboratory) for her support in the use of the Fourier Transform Infrared Spectrophotometer.

\section{REFERENCES}

[1] Ersoy B, Dikmen S, Yıldız A. Gören, R. Elitok Ö. Mineralogical and Physicochemical Properties of Talc from Emirdağ. Turkish J Earth Sci 2013; 22: 632-644.

[2] Grim RE, Clay Mineralogy, Int. Series in Earth Sciences. McGraw-Hill, 1968, New York.

[3] Deer WA, Howie RA \& Zussman J. An Introduction to the Rock-Forming Minerals. Longman Scientific \& Technical, 1992, Essex, UK.

[4] Nkoumbou C, Villieras F, Barres O, Bihannic I, Pelletier M, Razafitianamaharavo A, Metang V, Yonta Ngoune C, Njopwouo D, Yvon J. Physicochemical properties of talc ore from PoutKelle and Memel deposits (central Cameroon). Clay Minerals 2008b; 43: 317-337.

[5] Atluri V, Jina J, Shrimali K, Dang L, Wang X, Miller D. The hydrophobic surface state of talc as influenced by aluminum substitution in the tetrahedral layer. Journal of Colloid and Interface Science 2019; 536: 737-748.

[6] Yakovleva AA. Analysis of techniques for improving the adsorption capacity of talc. Protection of Metals and Physical Chemistry of Surfaces 2019; 55(3): 439-444.

[7] Gören R, Göçmez H, Özgür C. Synthesis of cordierite powder from talc, diatomite and alumina. Ceramic International 2006; 32: 407-409.

[8] Neto JBR, Moreno R, Rheological behaviour of kaolin/talc/alumina suspensions for manufacturing cordierite foams. Applied Clay Science, 2007; 3: 157-166.

[9] Mohan N, Agarwal A, Surfactants in Modern Applications. IJSRD-International Journal for Scientific Research \& Development 2019; 7(9): 69-73.

[10] Eastoe J. Surfactant Aggregation and Adsorption at Interfaces; in Colloid Science Principles, Methods and Applications (Ed.: T.Cosgrove), Blackwell Publishing, 2005, Oxford, pp.50-76.

[11] Knepper TP, Berna JL. Surfactants: Properties, Production, and Environmental Aspects Comprehensive. Analytical Chemistry 2003; 40:1-49.

[12] Haggerty GM, Bowman RS, Sorption of chromate and other inorganic anions by organo-zeolite. Environmental Science \& Technology 1994; 28(3): 452-458. 
[13] Gitipour S, Bowers MT, Huff W, Bodocs A. The efficiency of modified bentonite clays for removal of aromatic organics from oily liquid wastes, Spill Science \& Technology Bulletin 1997; 4(3): 155-164.

[14] Ersoy B, Çelik M.S. Uptake of aniline and nitrobenzenefrom aqueous solution by organo-Zeolite. Environmental Technology 2004; 25(3): 341-348.

[15] Wang CC, Juang LC, Lee CK, Hsu TC, Lee JF, Chao HP. Effects of exchanged surfactant cations on the pore structure and adsorption characteristics of montmorillonite. Journal of Colloid and Interface Science 2004; 280: 27-35.

[16] West CC, Harwell JH, Surfactants and subsurface remediation. Environmental Science \& Technology, 1992; 26(12): 2324-2330.

[17] García-Cervilla R, Santos A, Romero A, Lorenzo D. Compatibility of nonionic and anionic surfactants with persulfate activated by alkali in the abatement of chlorinated organic compounds in aqueous phase. Science of the Total Environment 2021; 751: 141782.

[18] Sanchez-Martin MJ, Dorado MC, Hoyo C, Rodríguez-Cruz MS, Influence of clay mineral structure and surfactant nature on the adsorption capacity of surfactants by clays. Journal of Hazardous Materials 2008; 150(1): 115-123.

[19] Karapanagioti HK, Sabatini DA, Bowman RS, Partitioning of hydrophobic organic chemicals (HOC) into anionic and cationic surfactant-modified sorbents. Water Research 2005; 39(4): 699709 .

[20] Rodriguez-Cruz MS, Sanchez-Martin MJ, Sanchez-Camazano M. A Comparative Study of Adsorption of an Anionic and a Non-Ionic Surfactant by soils based on physicochemical and mineralogical properties of soils. Chemosphere, 2005; 61, 1: 56-64.

[21] Atkin R, Craig VSJ, Wanless EJ, Biggs S. Mechanism of cationic surfactant adsorption at the solid-aqueous interface. Advances in Colloid and Interface Science, 2003; 103(3): 219-304.

[22] Yamaguchi Y, Hoffmann H. Interaction between saponite and cationic, zwitterionic and nonionic surfactants. Colloids and Surfaces A: Physicochemical and Engineering Aspects1997; 121: $67-80$.

[23] Özdemir O, Çınar M, Sabah E. Arslan F, Çelik MS. Adsorption of anionic surfactants onto sepiolite. Journal of Hazardous Materials 2007; 147: 625-632.

[24] Kaya A, Yukselen Y. Zeta potential of soils with surfactants and its relevance to electrokinetic remediation. Journal of Hazardous Materials B 2005; 120: 119-126.

[25] Oroscoa P, del Ruiz M, González J. Phase transformations of a talc ore under heated chlorine atmosphere. Thermochimica Acta 2013; 554: 15-24.

[26] Hoyo Del C, Dorado C, Rodriguez-Cruz MS, Sanchez-Martin MJ. Physicochemical study of selected surfactant-clay mineral systems, Journal of Thermal Analysis and Calorimetry, 2008; 94(1): 227-234.

[27] Breen C, Thompson G, Webb M. Preparation, thermal stability and decomposition routes of clay/Triton X-100 composites. Journal of Materials Chemistry, 1999; 9 (12): 3159. 
Dikmen et al. / Eskişehir Technical Univ. J. of Sci. and Tech. A-Appl. Sci. and Eng. Vol. 21-2020

[28] Zhang R, Somasundaran P. Advances in adsorption of surfactants and their mixtures at solid/solution interfaces. Advances in Colloid and Interface Science 2006; 123-126: 213-229.

[29] Madejova J. FTIR techniques in clay mineral studies. Vibrational Spectroscopy 2003; 31: 1-10. 